In November 1987, the General Assembly of the Member Universities approved the various proposals for research programmes and full activities which are due to start shortly. Particular attention to the programmes should be paid by naturalists and ecologists of all the member countries and especially by those who live in industrialized countries. Quite often supra-national organizations are oriented towards exporting the technical capacities of the 'developing' countries in order to increase their own production while improving the developing nations' economy. By doing so, the developed countries really help the economies of developing countries, but at the same time benefit themselves from such improvements.
The programmes of the new Community here described, in the section related to natural resources, should be oriented towards producing without destroying-producing within a framework of environmental protection and conservation. Growth there should be for the developing countries and by consequence for the developed; but it must be a growth without ecodisaster.

Aristeo Renzoni, Professor and Dean Dipartimento di Biologia Ambientale Università di Siena 53100 Siena, Italy.

\title{
The International Environmental Bureau
}

The International Environmental Bureau (IEB) is a specialized division of the International Chamber of Commerce (ICC), financed independently by industrial concerns from around the world. IEB's fundamental objective is to promote efficient environmental management for sustainable economic growth, and its primary purpose is to make available to companies everywhere the latest industrial expertise and techniques for managing environmental issues.

IEB serves as a trans-industry reference centre for environmental information on the control and abatement of pollution from industrial and commercial activity. As a non-profit entity, IEB does not charge for these information services, and indeed strives to encourage voluntary action by business leaders to improve their environmental performance. While IEB attempts to respond to requests for industrial information on pollution control technology to companies world-wide, we have tentatively identified 14 developing nations for priority attention: they are Argentina, Brazil, Egypt, Greece, India, Indonesia, Ivory Coast, Korea, Mexico, Nigeria, Portugal, Saudi Arabia, Thailand, and Turkey. For more information please write to the undersigned.

\section{Genetic Diversity}

There can scarcely be any expression that is better understood in the scientific community and yet not understood at all outside that group, than 'Genetic Diversity'. Many laymen believe that we should conserve Nature, but few can give a rational explanation of why they feel this way. What the scientists are saying is that the conservation of Nature is, inter alia and perhaps preeminently, for the purpose of maintaining into the future the choices that are now available to us for resolving the unpredictable problems which we shall have to face in a world of shrinking resources and burgeoning human population. In today's world, conservation is not just altruism, but rather a matter of future survival.

The living world can be likened to an iceberg: not only is it gradually melting away, but the greater, submerged part is quite unknown to us. The tip corresponds to the fraction of living species that science has recorded: some $1.5 \mathrm{mil}-$ lion. Estimates of the entire bulk vary from three to ten millions, and of this some 500,000 are 'melting away' and may be lost by the year AD 2000 -just 12 years from now. All possible conservation efforts should serve to keep the rate of 'melting' to a minimum. For who knows what species are faced with extinction? Could one of them, for instance, be the only bee that can pollinate the Brazil-nut tree (Bertholletia excelsa) or another be a grassy weed that might have helped us to breed a disease- or drought-resistant cereal?

We can neither predict what natural products we will require in the future, nor what plants, animals, or microorganisms, can provide us with new drugs, raw materials, or foodstuffs. Conservation allows us to have still a wide range of resources to call upon to face the changing world. For example, the qualities attributed to crop plants and livestock, such as yield and nutritional values, are rarely if ever permanent. As any farmer knows, they either "grow out' with succeeding generations, or pests evolve new strains and so overcome resistance. Continual breeding programmes, commonly using wild plants and animals, are thus essential to maintain yields. Nature mercifully offers surprises as to how some organism can become useful to Mankind (many Algae, for instance, may become valuable sources of protein). Who knows what other raw materials or services may thus be provided from the still-vast store of Nature.

Our perceptions of Nature vary from individual to individual. A tropical forest may offer quick profit and a cheap source of wood to some, a home for beautiful butterflies for others, or a watershed complete with Nature's own pumping-station (gravity) - a natural reservoir that will ensure fresh water for all time. Should short-term gains be allowed to breed long-term problems? Increasingly, decision-makers are wrestling with these questions. Even industrialists have come to recognize that if they harvest natural resources it must be done 'sustainably', or they will in time risk putting themselves out of business.

The world has become too crowded a place, and our demands are now too heavy, to expect Mother Nature to repair all the damages done by Man. But a World Conservation Strategy augmented by National Conservation Strategies such as already exist in over 30 nations world-wide, may finally provide the balance that has been missing between what we desire and what we can take safely (sus- 
tainably) from the environment. So why should we attempt to conserve what is left of natural areas world-wide? For four very good reasons:

Because we don't know what we would be losing if we did not.

Because we don't know what we will need.

Because we don't know what we will want and love.

And because the world will be a less varied and much poorer place if we lose these species and their ecosystems.

From 1-10 February 1988, scientists and conservationists, policymakers and bureaucrats, gathered in San José, Costa Rica, to form policy for a new edition of the World Conservation Strategy, which was first published in 1980. The scientists were attending technical workshops that addressed the future of the International Union for Conservation of Nature and Natural Resources (IUCN). The event was the 17 th General Assembly of IUCN (the world's largest scientific conservation organization), and genetic diversity was only one of the numerous topics that were debated. Indeed much of the information presented and garnered at these Assemblies has been shown to appear only months or years later in the popular media. The 17th General Assembly of IUCN featured an opening address by the Vice-President of IUCN, HRH The Duke of Edinburgh, and another by the latest Nobel Peace Prize Winner, President Oscar Arias of Costa Rica*.

DRAKE MCHugh, IUCN Media Coordinator
World Conservation Centre
Avenue du Mont-Blanc
CH-1196 Gland
Switzerland.

* See also the more detailed account which it is hoped to publish in the Conferences \& Meetings section of our Summer issue.Ed

\section{Ecosystem Theory and Application}

In his recent review of the above book in this Journal (Vol. 14, No. 3, pp. 283-4), Dr Mark O. Hill focused his attention on a claimed lack of any coherent account of ecosystem theory and application, on the variety of subjects treated in 20 chapters, and on the predominant individuality of the contributions. He concluded that readers had to look elsewhere for knowing what an ecosystem really is, and for disquisitions on productivity, nutrient cycling, and trophic webs.

In this present note we would like to point out that we have experienced the book as a useful source-book and a veritable storehouse of refreshing diversity for both fieldand class-work, as well as for library purposes. There is no shortage of well-documented textbooks aimed at synthesis and enabling the student to visualize the whole. This book's main intention has been to report on the investigations into various particular questions of ecosystems theory, while still containing a significant amount of diverse practical material. It is correct that the book is directed to an audience of students, specialists, or general readers with an educated interest in the discipline of ecology. It reunites so many different perspectives on ecosystem analysis and serves to pin-point the area. We feel therefore that it is more an enlightening cross-roads book than just a collection of chapters presented to an international congress and added to subsequently by the Editor. In other words, the more the individuality, the larger the choice.
For example, the Odums' papers give comprehensive studies on ecosystems (E.P. Odum), and on systems ecology and the enmergy method (H.T. Odum). Four chapters describe various types of ecosystems. The M.J. Winterbourn one on stream ecosystems is very penetrating, provides us with useful leads, and opens up ways to other fundamental studies on the subject. In addition, one can find chapters on geobotanical descriptions, applied ecology, biospheral ethic, and macroecology from an economic perspective.

As already stated by Dr Hill, several chapters are individually first-rate syntheses. But if the book does not present a picture of the terrestrial Biosphere as an entity, the separate parts of which are linked in a dynamic way as a result of constant changes in their living components, this is not so much a shortcoming as a presentation of its stimulating diversity.

Gonzague Pillet \& Gaye Bristow Centre for Human Ecology \&

Environmental Sciences

University of Geneva

P.O. Box 266

CH 1227 Carouge-Geneva

Switzerland.

\section{Go Back for the Future to Rehabilitate Landscape}

The landscape as we know it in much of Western Europe is rapidly disappearing with the changing environmentlargely as a result of our human ignorance. The landscape is made up of everything we see: vegetation and fields, woodlands and hedgerows, rivers, lakes and ponds, plants, animal wildlife, villages, towns and cities-not forgetting far too many carelessly wasteful humans. Satisfaction of Man's needs with large-scale farming techniques, endless quarrying and mining, and the construction of seemingly new motorways, has involved the uprooting of many of our hedgerows. These formed our field and village boundaries for centuries, supporting a marvellous diversity of plant and animal life, but we wonder for how much longer they will continue to do this?

Hedgerows are now rarely replanted when damaged or destroyed, but instead are being replaced by unsightly posts and rail fencing. Admittedly, this is cheaper than replanting hedgerows; but in the long-run it is far more costly in terms of devastation of wildlife habitats and natural amenities and beauty,

Badgers (Meles taxus) are one of the species which are worst hit and are now rarely seen in the English countryside. Not only are their setts being destroyed and Badgers harmed by our urban development etc., while a lot of them are killed by cars, but they are also taken for sport such as Badger baiting. Fortunately now some farmers are getting the message and are starting to take care of their hedgerows, so that in some cases fencing has been removed and replanting of hedgerows has taken place.

In our County of Cheshire we are encouraging farmers to carry out as much replanting as possible, whether it be of hedges or trees. In some cases we actually carry out the planting free of charge, but the farmer has to agree to maintain the trees himself after the first twelve months. In most of these cases, the farmer is entitled to a Forestry or Countryside Commission grant which is very encouraging. 